\title{
Coffee with a high content of chlorogenic acids and low content of hydroxyhydroquinone improves postprandial endothelial dysfunction in patients with borderline and stage 1 hypertension
}

\author{
Masato Kajikawa' ${ }^{1}$ Tatsuya Maruhashi ${ }^{2} \cdot$ Takayuki Hidaka $^{2}$ - Yukiko Nakano ${ }^{2}$ - Satoshi Kurisu ${ }^{2}$. Takeshi Matsumoto ${ }^{2}$. \\ Yumiko Iwamoto $^{2}$. Shinji Kishimoto ${ }^{2}$. Shogo Matsui ${ }^{2}$. Yoshiki Aibara ${ }^{3}$. Farina Mohamad Yusoff ${ }^{3}$. Yasuki Kihara ${ }^{2}$. \\ Kazuaki Chayama ${ }^{4}$. Chikara Goto ${ }^{5} \cdot$ Kensuke Noma $^{1,3}$. Ayumu Nakashima ${ }^{3} \cdot$ Takuya Watanabe $^{6} \cdot$ Hiroshi Tone $^{6}$. \\ Masanobu Hibi ${ }^{6} \cdot$ Noriko Osaki $^{6}$. Yoshihisa Katsuragi ${ }^{6}$. Yukihito Higashi ${ }^{1,3}$
}

Received: 6 September 2017 / Accepted: 6 January 2018 / Published online: 12 January 2018

( T) The Author(s) 2018. This article is an open access publication

\begin{abstract}
Purpose The purpose of this study was to evaluate acute effects of coffee with a high content of chlorogenic acids and different hydroxyhydroquinone contents on postprandial endothelial dysfunction.

Methods This was a single-blind, randomized, placebo-controlled, crossover-within-subject clinical trial. A total of 37 patients with borderline or stage 1 hypertension were randomized to two study groups. The participants consumed a test meal with a single intake of the test coffee. Subjects in the Study 1 group were randomized to single intake of coffee with a high content of chlorogenic acids and low content of hydroxyhydroquinone or coffee with a high content of chlorogenic acids and a high content of hydroxyhydroquinone with crossover. Subjects in the Study 2 group were randomized to single intake of coffee with a high content of chlorogenic acids and low content of hydroxyhydroquinone or placebo coffee with crossover. Endothelial function assessed by flow-mediated vasodilation and plasma concentration of 8-isoprostanes were measured at baseline and at 1 and $2 \mathrm{~h}$ after coffee intake.

Results Compared with baseline values, single intake of coffee with a high content of chlorogenic acids and low content of hydroxyhydroquinone, but not coffee with a high content of chlorogenic acids and high content of hydroxyhydroquinone or placebo coffee, significantly improved postprandial flow-mediated vasodilation and decreased circulating 8-isoprostane levels. Conclusions These findings suggest that a single intake of coffee with a high content of chlorogenic acids and low content of hydroxyhydroquinone is effective for improving postprandial endothelial dysfunction.

Clinical Trial Registration URL for Clinical Trial: https://upload.umin.ac.jp; Registration Number for Clinical Trial: UMIN000013283.
\end{abstract}

Keywords Chlorogenic acids $\cdot$ Hydroxyhydroquinone $\cdot$ Atherosclerosis $\cdot$ Endothelial function

Yukihito Higashi

yhigashi@hiroshima-u.ac.jp

1 Division of Regeneration and Medicine, Medical Center for Translational and Clinical Research, Hiroshima University Hospital, Hiroshima, Japan

2 Department of Cardiovascular Medicine, Graduate School of Biomedical and Health Sciences, Hiroshima University, Hiroshima, Japan

3 Department of Cardiovascular Regeneration and Medicine, Research Institute for Radiation Biology and Medicine
(RIRBM), Hiroshima University, 1-2-3 Kasumi, Minami-ku, Hiroshima 734-8551, Japan

4 Department of Gastroenterology and Metabolism, Graduate School of Biomedical and Health Sciences, Hiroshima University, Hiroshima, Japan

5 Department of Physical Therapy, Hiroshima International University, Hiroshima, Japan

6 Health Care Food Research Laboratories, Kao Corporation, Tokyo, Japan 


\section{Introduction}

Endothelial dysfunction occurs in the early stage of atherosclerosis and plays an important role in the development of atherosclerotic conditions, resulting in cardiovascular complications $[1,2]$. Measurements of flow-mediated vasodilation (FMD) as an index of endothelium-dependent vasodilation in the brachial artery have been widely used in clinical research to evaluate endothelial function [3-6]. Endothelial dysfunction has been shown to be an independent predictor of cardiovascular events [7-10]. Postprandial hyperglycemia is associated with endothelial dysfunction and is a risk factor for cardiovascular events [11, 12]. Acute hyperglycemia induces oxidative stress, which is a key trigger of endothelial dysfunction by reducing nitric oxide (NO) bioavailability $[11,12]$. Therefore, it is important to determine interventions that can restore endothelial function under the condition of postprandial hyperglycemia.

Coffee is a popular beverage that is consumed worldwide. Coffee contains an abundance of polyphenols, which is the major source of dietary antioxidants [13, 14]. Drinking coffee is associated with lower risks of metabolic syndrome, diabetes, and coronary heart disease [15-19]. However, there have been conflicting results regarding the association between coffee drinking and risk of cardiovascular disease [19-23]. The effect of coffee on endothelial function is also controversial [24-27]. One possible reason for the different results of studies is that the contents of chlorogenic acids, which are the most abundant antioxidants in coffee, may vary depending on several factors [16]. Coffee has a complex chemical mixture with hundreds of compounds. Roasting coffee results in the loss of chlorogenic acids and generation of hydroxyhydroquinone [28]. A previous study showed that hydroxyhydroquinone inhibits the chlorogenic acid-induced restoration of endothelial function in a rat model of hypertension [29]. It has also been shown that hydroxyhydroquinone increased the production of reactive oxygen species in a dose-dependent manner [30]. Some clinical studies have shown that coffee with a high content of chlorogenic acids and a low content of hydroxyhydroquinone is effective for reducing blood pressure $[31,32]$.

However, there is no information on the effects of a combination of chlorogenic acids and hydroxyhydroquinone on endothelial function in humans. Therefore, in this study, we evaluated acute effects of coffee with a high content of chlorogenic acids and different contents of hydroxyhydroquinone on endothelial function, especially postprandial endothelial dysfunction, in patients with borderline or stage 1 hypertension.

\section{Materials and methods}

\section{Subjects}

Between October 2014 and January 2016, we enrolled 37 patients with borderline or stage 1 hypertension at Hiroshima University Hospital. The inclusion criteria were as follows: (1) patients with borderline or stage 1 hypertension, (2) 30 years of age or older, (3) non-smoker, and (4) alcohol intake $\leq 20 \mathrm{~g} /$ day. The exclusion criteria were as follows: (1) patients with diabetes mellitus, (2) treatment with renin angiotensin system inhibitors or statins, and (3) premenopausal women. It is well known that RAS inhibitors, but not calcium channel blockers, significantly influence the value of FMD [33]. Therefore, subjects on calcium channel blockers were not excluded in this study. None of participants took any medications other than calcium channel blockers. Borderline hypertension was defined as systolic blood pressure of $130-139 \mathrm{mmHg}$ or diastolic blood pressure of $85-89 \mathrm{mmHg}$. Stage 1 hypertension was defined as systolic blood pressure of $140-159 \mathrm{mmHg}$ or diastolic blood pressure of 90-99 mmHg [34]. Diabetes mellitus was defined according to the American Diabetes Association [35]. Dyslipidemia was defined according to the third report of the National Cholesterol Education Program [36]. This study was approved by the ethical committees of Hiroshima University. All subjects gave written informed consent for participation in the study.

\section{Study protocol}

This was a single-blind, randomized, placebo-controlled, crossover-within-subject clinical trial. A total of 37 subjects were randomized to Study 1 group or Study 2 group (Fig. 1). Study 1 group was randomized to single intake of beverage A (chlorogenic acids: $412 \mathrm{mg}$, hydroxyhydroquinone: $0.11 \mathrm{mg}$, and caffeine: $69 \mathrm{mg}$ ) or beverage B (chlorogenic acids: $373 \mathrm{mg}$, hydroxyhydroquinone: $0.76 \mathrm{mg}$, and caffeine: $75 \mathrm{mg}$ ) with crossover. Study 2 group was randomized to single intake of beverage $\mathrm{A}$ or beverage $\mathrm{C}$ (chlorogenic acids: $0 \mathrm{mg}$, hydroxyhydroquinone: $0.1 \mathrm{mg}$, and caffeine: $59 \mathrm{mg}$ ) with crossover. Each study was separated by a washout period of at least 7 days. The scientific conduct of the study (design, implementation, analysis and interpretation of the data) and manuscript preparation were independent of the sponsor. The subjects were instructed to avoid alcohol, coffee, and food containing chlorogenic acids for $24 \mathrm{~h}$ before the study, to abstain from eating for $12 \mathrm{~h}$ before the study and to drink only commercially available bottled water for $24 \mathrm{~h}$ before the study. The study began at 8:30 AM. Measurement of FMD was 
Fig. 1 Flow chart of study design

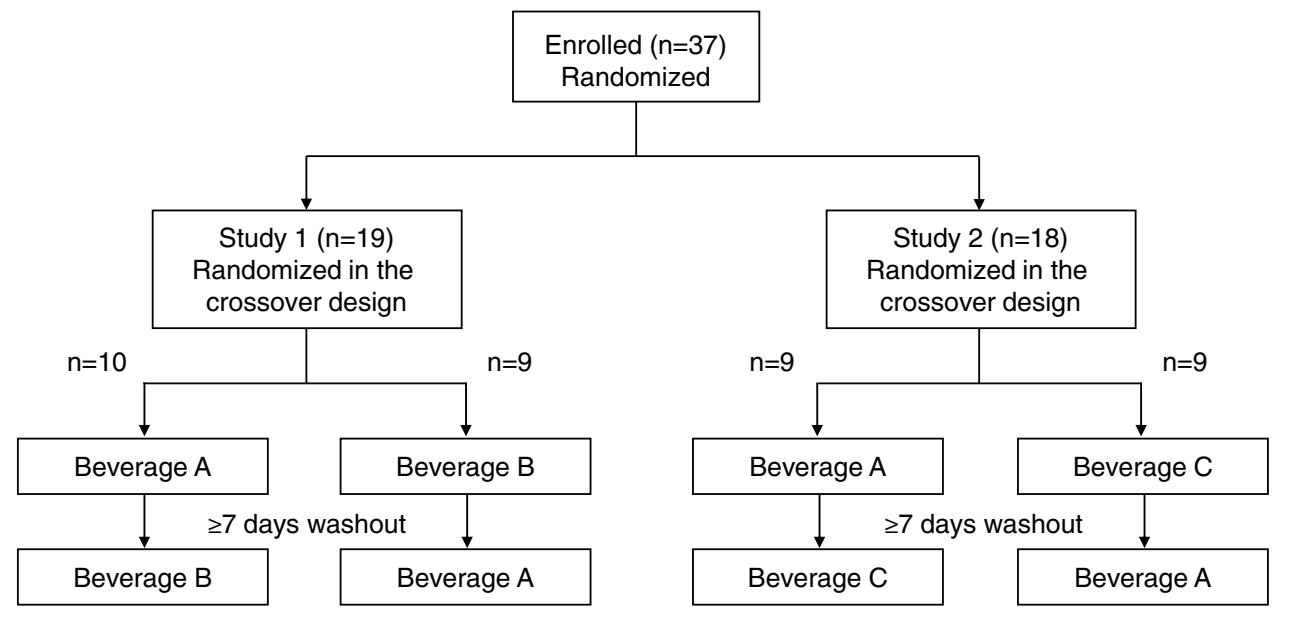

performed while each subject was in the supine position in a quiet, dark, air-conditioned room (constant temperature of $22-25^{\circ} \mathrm{C}$ ). Venous blood samples were obtained from the left antecubital vein. The subjects then ingested a test meal (592 kcal/115 g, carbohydrate:fat:protein =75.0:28. 5:8.0 g, Meal Test C; Saraya Co, Ltd, Osaka, Japan) with a single intake of a test beverage within $12 \mathrm{~min}$. Blood samples were collected and FMD was measured at 1 and $2 \mathrm{~h}$ after ingestion. Chlorogenic acids in plasma were measured by liquid chromatography-tandem mass spectrometry. Plasma 8-isoprostane levels were measured using an EIA kit (Cayman Chemical Co., Ann Arbor, MI, USA).

\section{Test beverages}

Ordinary coffee contains variable amounts of chlorogenic acids depending on the coffee bean species, brewing conditions, and roasting method. Darker roasts contain a smaller amount of chlorogenic acids [16]. Hydroxyhydroquinone is a compound that is generated from the roasting of coffee beans [28]. Direct measurements of commercially available brewed coffee showed that less than $200 \mathrm{mg}$ chlorogenic acids is generally contained in one serving [37]. The beverages were manufactured industrially (Kao Co. Tokyo, Japan) and were taste- and flavor-matched (coffee-flavored). The compositions of the test beverages are shown in Table 1.
Beverage A was roasted coffee for which an absorption purification process was used to remove hydroxyhydroquinone by active carbon, maintaining a large amount of chlorogenic acids. Beverage B was ordinary brewed coffee containing chlorogenic acids and hydroxyhydroquinone. Beverage $\mathrm{C}$ was an artificial placebo beverage prepared by using coffeeflavored agents.

\section{Measurement of FMD}

A high-resolution ultrasonography (UNEXEF18G, UNEX Co, Nagoya, Japan) was used to evaluate FMD. The protocol for measurements of FMD have been described in detail previously [38]. Briefly, the longitudinal image of the brachial artery was assessed before and after generation of vascular response to reactive hyperemia by a 5 -min period of forearm occlusion to evaluate FMD. FMD was defined as the maximal percentage change in vessel diameter from the baseline value.

\section{Statistical analysis}

Results are presented as means \pm SD for continuous variables and as percentages for categorical variables. Statistical significance was set at a level of $P<0.05$. Comparison of continuous variables between 2 groups was performed
Table 1 Composition of the intervention products

\begin{tabular}{llll}
\hline & Beverage A & Beverage B & Beverage C \\
\hline Drink volume, g/serving & 185 & 185 & 185 \\
Chlorogenic acids (9 analogues), mg/serving & 412 & 378 & 0 \\
Hydroxyhydroquinone, mg/serving & 0.11 & 0.76 & 0.10 \\
Caffeine, mg/serving & 69 & 75 & 59 \\
Energy, kcal/serving & 9 & 11 & 2 \\
\hline
\end{tabular}

Chlorogenic acids (9 analogues) analogues present are the caffeoylquinic acids (3-CQA, 4-CQA, and 5-CQA), feruloylquinic acids (3-CQA, 4-CQA, and 5-CQA), and dicaffeoylquinic acids (3,4-di-CQA, 3,5-di-CQA, and 4,5-di-CQA) 
using the Student's t test or the Chi-squared test for categorical data. Changes in FMD and parameters between before and after drinking test beverages were evaluated using paired $t$ test. Differences in FMD and parameters between beverage A and beverage $\mathrm{B}$, and beverage $\mathrm{A}$ and beverage $C$ were evaluated using repeated measures ANOVA with Tukey's post hoc test. Relations between variables were determined by Pearson's correlation analysis. The data were processed using the software package Stata version 9 (Stata Co., College Station, Texas, USA).

\section{Results}

\section{Clinical characteristics}

Baseline characteristics of Study 1 group and Study 2 group are summarized in Table 2. Baseline characteristics in the two groups were similar. All participants reported that they adhered to dietary restrictions, which was confirmed by low concentrations of plasma chlorogenic acids at baseline (Table 3). All participants completed the trial.

Table 2 Clinical characteristics of the subjects

\begin{tabular}{|c|c|c|}
\hline Variables & Study $1(n=19)$ & Study $2(n=18)$ \\
\hline Age, year & $53 \pm 19$ & $56 \pm 15$ \\
\hline Sex, men/women & $14 / 5$ & $12 / 6$ \\
\hline Body mass index, $\mathrm{kg} / \mathrm{m}^{2}$ & $24.5 \pm 4.1$ & $23.2 \pm 3.1$ \\
\hline Systolic blood pressure, $\mathrm{mmHg}$ & $130 \pm 11$ & $128 \pm 13$ \\
\hline Diastolic blood pressure, $\mathrm{mmHg}$ & $77 \pm 9$ & $81 \pm 8$ \\
\hline Heart rate, bpm & $65 \pm 8$ & $63 \pm 9$ \\
\hline HbA1c, $\%$ & $5.4 \pm 0.3$ & $5.5 \pm 0.4$ \\
\hline \multicolumn{3}{|l|}{ Medical history, $n(\%)$} \\
\hline Borderline hypertension & $6(31.6)$ & $3(16.7)$ \\
\hline Stage 1 hypertension & $13(68.4)$ & $15(83.3)$ \\
\hline Dyslipidemia & $9(47.4)$ & $7(38.9)$ \\
\hline Diabetes mellitus & $0(0)$ & $0(0)$ \\
\hline Previous coronary heart disease & $0(0)$ & $0(0)$ \\
\hline Previous stroke & $0(0)$ & $0(0)$ \\
\hline Current smoker & $0(0)$ & $0(0)$ \\
\hline \multicolumn{3}{|l|}{ Medications, $n(\%)$} \\
\hline Calcium-channel blockers & $7(36.7)$ & $9(50.0)$ \\
\hline $\begin{array}{l}\text { Renin angiotensin system } \\
\text { inhibitors }\end{array}$ & $0(0)$ & $0(0)$ \\
\hline Statins & $0(0)$ & $0(0)$ \\
\hline \multicolumn{3}{|l|}{ Medically treated diabetes } \\
\hline Any & $0(0)$ & $0(0)$ \\
\hline Insulin-dependent & $0(0)$ & $0(0)$ \\
\hline
\end{tabular}

Results are presented as mean \pm SD or number (\%)
Table 3 FMD values at baseline and during follow-up

\begin{tabular}{|c|c|c|c|c|}
\hline & \multicolumn{2}{|l|}{ Study 1} & \multicolumn{2}{|l|}{ Study 2} \\
\hline & Beverage A & Beverage B & Beverage A & Beverage $\mathrm{C}$ \\
\hline \multicolumn{5}{|c|}{ Systolic blood pressure, $\mathrm{mmHg}$} \\
\hline Baseline & $130 \pm 11$ & $131 \pm 11$ & $128 \pm 13$ & $130 \pm 14$ \\
\hline $1 \mathrm{~h}$ & $131 \pm 13$ & $128 \pm 11$ & $129 \pm 12$ & $132 \pm 16$ \\
\hline $2 \mathrm{~h}$ & $130 \pm 12$ & $129 \pm 13$ & $128 \pm 16$ & $129 \pm 16$ \\
\hline \multicolumn{5}{|c|}{ Chlorogenic acid, ng/mL } \\
\hline Baseline & $0.7 \pm 2.0$ & $1.1 \pm 3.0$ & $1.1 \pm 2.7$ & $0.7 \pm 2.8$ \\
\hline $1 \mathrm{~h}$ & $54.0 \pm 20.5^{*}$ & $56.5 \pm 22.7^{*}$ & $51.5 \pm 22.5^{*}$ & $0.3 \pm 1.3 \dagger$ \\
\hline $2 \mathrm{~h}$ & $50.3 \pm 16.0^{*}$ & $55.1 \pm 23.3 *$ & $56.7 \pm 21.2^{*}$ & $0.3 \pm 1.2 \dagger$ \\
\hline \multicolumn{5}{|c|}{ Triglycerides, mg/dL } \\
\hline Baseline & $124 \pm 63$ & $117 \pm 65$ & $121 \pm 67$ & $111 \pm 49$ \\
\hline $1 \mathrm{~h}$ & $159 \pm 76^{*}$ & $143 \pm 72 *$ & $140 \pm 66^{*}$ & $132 \pm 48^{*}$ \\
\hline $2 \mathrm{~h}$ & $181 \pm 90^{*}$ & $188 \pm 104^{*}$ & $174 \pm 74^{*}$ & $167 \pm 64^{*}$ \\
\hline \multicolumn{5}{|c|}{ Glucose, $\mathrm{mg} / \mathrm{dL}$} \\
\hline Baseline & $95 \pm 10$ & $93 \pm 6$ & $92 \pm 8$ & $92 \pm 7$ \\
\hline $1 \mathrm{~h}$ & $140 \pm 32 *$ & $139 \pm 32 *$ & $124 \pm 23^{*}$ & $130 \pm 22 *$ \\
\hline $2 \mathrm{~h}$ & $120 \pm 29 *$ & $122 \pm 24 *$ & $112 \pm 16^{*}$ & $110 \pm 18^{*}$ \\
\hline \multicolumn{5}{|c|}{ Insulin, $\mu \mathrm{IU} / \mathrm{L}$} \\
\hline Baseline & $7 \pm 5$ & $6 \pm 4$ & $6 \pm 4$ & $6 \pm 3$ \\
\hline $1 \mathrm{~h}$ & $55 \pm 39 *$ & $51 \pm 36^{*}$ & $42 \pm 39 *$ & $42 \pm 27 *$ \\
\hline $2 \mathrm{~h}$ & $41 \pm 28^{*}$ & $45 \pm 46^{*}$ & $26 \pm 22^{*}$ & $27 \pm 25^{*}$ \\
\hline \multicolumn{5}{|c|}{ 8-Isoprostane, $\mathrm{pg} / \mathrm{mL}$} \\
\hline Baseline & $75 \pm 48$ & $55 \pm 23$ & $88 \pm 67$ & $73 \pm 57$ \\
\hline $1 \mathrm{~h}$ & $56 \pm 41$ & $59 \pm 46$ & $75 \pm 67 *$ & $55 \pm 23$ \\
\hline $2 \mathrm{~h}$ & $73 \pm 60$ & $69 \pm 74$ & $72 \pm 59^{*}$ & $64 \pm 32$ \\
\hline \multicolumn{5}{|c|}{ High-sensitivity C-reactive protein, $\mathrm{mg} / \mathrm{dL}$} \\
\hline Baseline & $0.10 \pm 0.17$ & $0.05 \pm 0.04$ & $0.07 \pm 0.07$ & $0.08 \pm 0.17$ \\
\hline $1 \mathrm{~h}$ & $0.10 \pm 0.17$ & $0.05 \pm 0.04$ & $0.07 \pm 0.07$ & $0.09 \pm 0.21$ \\
\hline $2 \mathrm{~h}$ & $0.10 \pm 0.16$ & $0.05 \pm 0.04$ & $0.07 \pm 0.07$ & $0.11 \pm 0.25$ \\
\hline \multicolumn{5}{|l|}{ FMD, \% } \\
\hline Baseline & $4.5 \pm 4.0$ & $5.4 \pm 4.8$ & $3.1 \pm 3.6$ & $4.2 \pm 3.6$ \\
\hline $1 \mathrm{~h}$ & $5.4 \pm 4.5^{*}$ & $4.9 \pm 4.6$ & $4.9 \pm 2.1^{*}$ & $4.1 \pm 3.3$ \\
\hline $2 \mathrm{~h}$ & $6.0 \pm 2.4^{*}$ & $6.4 \pm 4.4$ & $4.6 \pm 3.4^{*}$ & $3.8 \pm 3.7$ \\
\hline
\end{tabular}

$* P<0.05$ vs. baseline

${ }^{\dagger} P<0.05$ vs. Beverage A

\section{Effects of beverages on parameters and endothelial function}

\section{Study 1}

Absolute changes in parameters after drinking test beverages are shown in Table 3. There were no significant differences in baseline and postprandial parameters at each observation time point between beverage A and beverage B (Table 3). The concentrations of triglycerides, glucose, insulin, and chlorogenic acid were significantly increased compared with baseline values at $1 \mathrm{~h}$ and at $2 \mathrm{~h}$ after ingestion of beverage $\mathrm{A}$ and after ingestion of beverage B. Single intake of 
beverage A significantly increased FMD from $4.5 \pm 4.0 \%$ to $5.4 \pm 4.5 \%$ at $1 \mathrm{~h}$ (an increase of $20 \%, P=0.03$ ) and to $6.0 \pm 2.4 \%$ at $2 \mathrm{~h}$ (an increase of $33 \%, P=0.04$ ). FMD and 8 -isoprostane were not different from baseline values after drinking beverage B. There were no significant differences in other postprandial parameters between beverage $A$ and beverage B (Table 3).

\section{Study 2}

There were no significant differences in systolic blood pressure, triglycerides, glucose, insulin, 8-isoprostane, hs-CRP, and FMD at each observation time point between beverage $\mathrm{A}$ and beverage $\mathrm{C}$ (Table 3). The plasma chlorogenic acid concentrations were significantly higher after ingestion of beverage A than after ingestion of beverage $\mathrm{C}$ (Table 3). The concentrations of triglycerides, glucose, and insulin were significantly increased compared with baseline values at 1 and at $2 \mathrm{~h}$ after ingestion of beverage $\mathrm{A}$ and after ingestion of beverage C. Single intake of beverage A significantly increased FMD from $3.1 \pm 3.6$ to $4.9 \pm 2.1 \%$ at $1 \mathrm{~h}$ (an increase of $58 \%, P=0.02$ ) and to $4.6 \pm 3.4 \%$ at $2 \mathrm{~h}$ (an increase of $48 \%, P=0.02$ ) and significantly decreased serum level of 8 -isoprostane from $88 \pm 67$ to $75 \pm 67 \mathrm{pg} / \mathrm{mL}$ at $1 \mathrm{~h}$ $(P=0.03)$ and to $72 \pm 59 \mathrm{pg} / \mathrm{mL}$ at $2 \mathrm{~h}(P=0.02)$ (Table 3$)$.

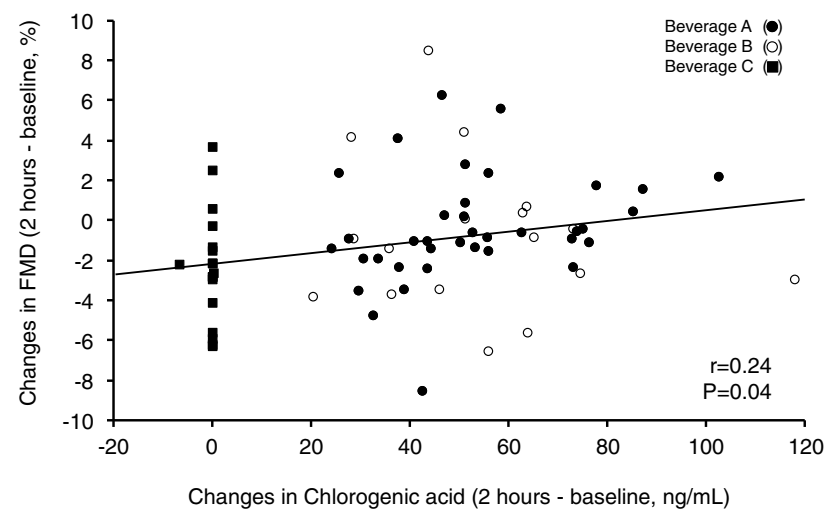

Fig. 2 Scatter plot shows the relationships between postprandial changes in FMD and postprandial changes in chlorogenic acid
FMD and 8-isoprostane were not different from baseline values after drinking beverage $\mathrm{C}$. There were no significant differences in postprandial parameters between beverage $\mathrm{A}$ and beverage $\mathrm{C}$ (Table 3 ).

\section{Correlations between parameters and endothelial function}

Changes in FMD were positively correlated with changes in chlorogenic acids after drinking test beverages (Fig. 2). Changes in FMD after ingestion of beverage A were positively correlated with 8 -isoprostane at baseline, while changes in FMD after ingestion of beverage $\mathrm{C}$ were not correlated with 8-isoprostane at baseline (Fig. 3a, b).

\section{Discussion}

This study is the first single-blind, randomized, placebocontrolled, crossover trial to evaluate the acute effects of coffee with a high content of chlorogenic acids and different contents of hydroxyhydroquinone on postprandial endothelial dysfunction in patients with borderline or stage 1 hypertension. A single intake of coffee with a high content of chlorogenic acids and low content of hydroxyhydroquinone restored postprandial endothelial dysfunction by decreasing in oxidative stress.

Epidemiologic studies have shown that coffee drinking is associated with lower risk of cardiovascular disease [15, 17-19]. In the present study, single intake of coffee with a high content of chlorogenic acids and low content of hydroxyhydroquinone, but not single intake of coffee with a high content of chlorogenic acids and high content of hydroxyhydroquinone or placebo coffee, significantly improved postprandial endothelial dysfunction. In addition, changes in FMD after drinking the test beverage with a high content of chlorogenic acids and low content of hydroxyhydroquinone positively correlated with changes in levels of chlorogenic acids. These findings suggest that dietary intake of coffee with a high content of chlorogenic acids and low content of
Fig. 3 Scatter plots show the relationships between postprandial changes in FMD (a $1 \mathrm{~h}$ after ingestion, $\mathbf{b} 2 \mathrm{~h}$ after ingestion) and 8-isoprostane at baseline
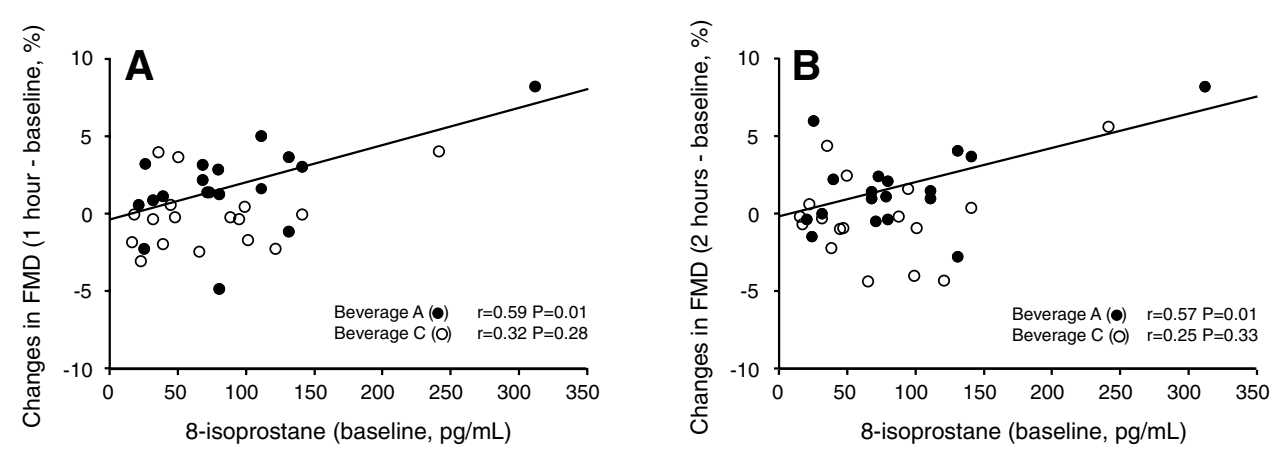
hydroxyhydroquinone is a healthy habit to improve endothelial function.

Oxidative stress has been shown to play a critical role in the maintenance and development of endothelial dysfunction by reducing the bioavailability of $\mathrm{NO}[1,2]$. Plasma levels of 8-isoprostane, a marker of oxidative stress, were increased in patients with vascular disease [39]. In the present study, single intake of coffee with a high content of chlorogenic acids and low content of hydroxyhydroquinone, but not single intake of coffee with a high content of chlorogenic acids and high content of hydroxyhydroquinone or placebo coffee, decreased circulating 8-isoprostane levels. In addition, coffee with a high content of chlorogenic acids and low content of hydroxyhydroquinone improved FMD in patients who had high levels of 8 -isoprostane. These findings suggest that the beneficial effects of coffee with a high content of chlorogenic acids and low level of hydroxyhydroquinone on endothelial function are induced, at least in part, by a decrease in oxidative stress.

A major compound in coffee is caffeine. It is well known that caffeine influences systemic hemodynamics, including elevation of blood pressure and vascular function [40, 41]. Although both coffee with and without caffeine have similar associations with cardiovascular disease [15, 42], in the present study, to avoid the effects of caffeine on systemic hemodynamics and endothelial function, the test beverages contained the same amounts of caffeine.

A recent meta-analysis revealed antihypertensive effects of chlorogenic acids [43]. Suzuki et al. [29] reported that hydroxyhydroquinone inhibits the antihypertensive effect of chlorogenic acids in spontaneous hypertensive rats. These findings suggest that coffee with a high content of chlorogenic acids and low content of hydroxyhydroquinone has a beneficial effect in patients with hypertension. Indeed, longterm intake of coffee with a high content of chlorogenic acids and low content of hydroxyhydroquinone was shown to be effective for reducing blood pressure in patients with mild hypertension [31,32]. Therefore, we enrolled patients with borderline or stage 1 hypertension in this study. In the present study, acute intake of coffee with a high content of chlorogenic acids and low content of hydroxyhydroquinone did not alter blood pressure in these subjects (Table 3). Several investigators, including us, have reported that caffeine intake is associated with acute increase in blood pressure [40, 41]. Conversely, chronic caffeine consumption was shown to have no significant effect on blood pressure [41]. In the case of acute coffee intake, interaction of chlorogenic acids and caffeine may regulate changes in blood pressure. It is likely that the antioxidant effect of chlorogenic acids, not the blood pressure-lowering effect of chlorogenic acids, is involved in the restoration of postprandial endothelial dysfunction.
Some studies have shown that acute administration of coffee has a harmful effect on endothelial function in healthy subjects [24, 25], while other studies have shown that coffee improves endothelial function $[26,27]$. In addition, the association between coffee drinking and risk of cardiovascular disease remains inconclusive [15, 17-23]. The reason for the controversial results remains unclear. Hydroxyhydroquinone inhibits the chlorogenic acid-induced restoration of endothelial function and increases production of reactive oxygen species in a dose-dependent manner [29, 30]. To evaluate the effects of hydroxyhydroquinone on endothelial function, we compared the effects of coffees with a high content of chlorogenic acids and different contents of hydroxyhydroquinone in Study 1. We confirmed that intake of coffee with a high content of chlorogenic acids and low content of hydroxyhydroquinone, but not intake of coffee with a high content of chlorogenic acids and high content of hydroxyhydroquinone, improved postprandial endothelial dysfunction. Intake of coffee with reduced hydroxyhydroquinone per se also may be beneficial for maintenance of vascular function and prevention of cardiovascular events.

\section{Study limitations}

The present study has a number of limitations. First, the number of patients was relatively small. A single-blind, randomized, placebo-controlled, crossover trial was performed to increase the power of the study. We confirmed that a single intake of coffee with a high content of chlorogenic acids and low content of hydroxyhydroquinone was effective for restoring postprandial endothelial dysfunction in both Study 1 and Study 2. Second, we evaluated the acute effects of chlorogenic acids and chlorogenic acids with different hydroxyhydroquinone contents on endothelial function. Long-term interventions are needed to determine whether acute effects of coffee with a high content of chlorogenic acids and low content of hydroxyhydroquinone are sustained over time. Third, coffee is a rich source of chlorogenic acids, which have strong anti-inflammatory properties $[13,14]$. Inflammation also plays a critical role in endothelial dysfunction $[44,45]$. In the present study, there were no significant differences in serum levels of highsensitivity $\mathrm{C}$-reactive protein between beverage $\mathrm{A}$ and beverage $\mathrm{B}$ (Table 3 ). It is unlikely that inflammation contributes to high content of chlorogenic acid-induced improvement in postprandial vascular injury. Fourth, we had no information on the participants' coffee consumption background. Although we confirmed that the concentrations of plasma chlorogenic acids at baseline were low, we cannot deny the possibility that the participants' coffee consumption background affected the results of the study. Finally, coffee contains hundreds of compounds that might affect endothelial 
function. We cannot rule out the possibility that compounds other than chlorogenic acids and hydroxyhydroquinone have a greater influence on endothelial function.

In conclusion, a single intake of coffee with a high content of chlorogenic acids and low hydroxyhydroquinone is effective for improving postprandial endothelial dysfunction. Further studies are needed to assess the long-term effects of drinking coffee with a high content of chlorogenic acids and low content of hydroxyhydroquinone on vascular function, onset of cardiovascular disease, and cardiovascular events.

Acknowledgements We thank Miki Kumiji, Megumi Wakisaka, Ki-ichiro Kawano, and Satoko Michiyama of Hiroshima University, Research Institute for Radiation Biology and Medicine, for their excellent secretarial assistance.

Author contributions $\mathrm{MK}$, and $\mathrm{YH}$, drafting the article and conception of this study; MK, TM, HT, YN, SK, TM, YI, AI, SK, SM, YI, FMY, $\mathrm{CG}, \mathrm{KN}, \mathrm{AN}, \mathrm{TW}, \mathrm{HT}, \mathrm{MH}, \mathrm{NO}$, and $\mathrm{YK}$, acquisition of data; $\mathrm{YK}$, and $\mathrm{KC}$, revising the article critically for important intellectual content. $\mathrm{YH}$ is the guarantor of this work and, as such, had full access to all the data in the study and takes responsibility for the integrity of the data and the accuracy of the data analysis. All authors read and approved the final manuscript.

Funding This study was supported financially by Kao Corporation.

Open Access This article is distributed under the terms of the Creative Commons Attribution 4.0 International License (http://creativecommons.org/licenses/by/4.0/), which permits unrestricted use, distribution, and reproduction in any medium, provided you give appropriate credit to the original author(s) and the source, provide a link to the Creative Commons license, and indicate if changes were made.

\section{References}

1. Ross R (1999) Atherosclerosis-an inflammatory disease. N Engl J Med 340:115-126

2. Higashi Y, Noma K, Yoshizumi M, Kihara Y (2009) Oxidative stress and endothelial function in cardiovascular diseases. Circ J 73:411-418

3. Celermajer DS, Sorensen KE, Gooch VM, Spiegelhalter DJ, Miller OI, Sullivan ID, Lloyd JK, Deanfield JE (1992) Non-invasive detection of endothelial dysfunction in children and adults at risk of atherosclerosis. Lancet 340:1111-1115

4. Corretti MC, Anderson TJ, Benjamin EJ, Celermajer D, Charbonneau F, Creager MA, Deanfield J, Drexler H, Gerhard-Herman M, Herrington D, Vallance P, Vita J, Vogel R; International Brachial Artery Reactivity Task Force (2002) Guidelines for the ultrasound assessment of endothelial-dependent flow-mediated vasodilation of the brachial artery: a report of the International Brachial Artery Reactivity Task Force. J Am Coll Cardiol 39:257-265

5. Benjamin EJ, Larson MG, Keyes MJ, Mitchell GF, Vasan RS, Keaney JF Jr, Lehman BT, Fan S, Osypiuk E, Vita JA (2004) Clinical correlates and heritability of flow-mediated dilation in the community: the Framingham Heart Study. Circulation 109:613-619

6. Kajikawa M, Oda N, Kishimoto S, Maruhashi T, Iwamoto Y, Iwamoto A, Matsui S, Aibara Y, Yusoff MF, Hidaka T, Kihara Y,
Chayama K, Goto C, Noma K, Nakashima A, Taguchi A, Higashi Y (2017) Increasing risk of osteoporotic fracture is associated with vascular dysfunction and abnormal vascular structure in both men and women. Circ J 81:862-869

7. Modena MG, Bonetti L, Coppi F, Bursi F, Rossi R (2002) Prognostic role of reversible endothelial dysfunction in hypertensive postmenopausal women. J Am Coll Cardiol 40:505-510

8. Gokce N, Keaney JF Jr, Hunter LM, Watkins MT, Menzoian JO, Vita JA (2002) Risk stratification for postoperative cardiovascular events via noninvasive assessment of endothelial function: a prospective study. Circulation 105:1567-1572

9. Lerman A, Zeiher AM (2005) Endothelial function: cardiac events. Circulation 111:363-368

10. Morimoto H, Kajikawa M, Oda N, Idei N, Hirano H, Hida E, Maruhashi T, Iwamoto Y, Kishimoto S, Matsui S, Aibara Y, Hidaka T, Kihara Y, Chayama K, Goto C, Noma K, Nakashima A, Ukawa T, Tsuji T, Higashi Y (2016) Endothelial function assessed by automatic measurement of enclosed zone flow-mediated vasodilation using an oscillometric method is an independent predictor of cardiovascular events. J Am Heart Assoc 5:e004385

11. Loader J, Montero D, Lorenzen C, Watts R, Méziat C, Reboul C, Stewart S, Walther G (2015) Acute hyperglycemia impairs vascular function in healthy and cardiometabolic diseased subjects: systematic review and meta-analysis. Arterioscler Thromb Vasc Biol 35:2060-2072

12. Mah E, Bruno RS (2012) Postprandial hyperglycemia on vascular endothelial function: mechanisms and consequences. Nutr Res $32: 727-740$

13. Gómez-Ruiz JA, Leake DS, Ames JM (2007) In vitro antioxidant activity of coffee compounds and their metabolites. J Agric Food Chem 55:6962-6969

14. Fukushima Y, Ohie T, Yonekawa Y, Yonemoto K, Aizawa H, Mori Y, Watanabe M, Takeuchi M, Hasegawa M, Taguchi C, Kondo K (2009) Coffee and green tea as a large source of antioxidant polyphenols in the Japanese population. J Agric Food Chem 57:1253-1259

15. Freedman ND, Park Y, Abnet CC, Hollenbeck AR, Sinha R (2012) Association of coffee drinking with total and cause-specific mortality. N Engl J Med 366:1891-1904

16. Martini D, Del Bo' C, Tassotti M, Riso P, Del Rio D, Brighenti F, Porrini M (2016) Coffee consumption and oxidative stress: a review of human intervention studies. Molecules 21:E979

17. van Dam RM, Feskens EJ (2002) Coffee consumption and risk of type 2 diabetes mellitus. Lancet 360:1477-1478

18. Hino A, Adachi H, Enomoto M, Furuki K, Shigetoh Y, Ohtsuka M, Kumagae S, Hirai Y, Jalaldin A, Satoh A, Imaizumi T (2007) Habitual coffee but not green tea consumption is inversely associated with metabolic syndrome: an epidemiological study in a general Japanese population. Diabetes Res Clin Pract 76:383-389

19. Ding M, Bhupathiraju SN, Satija A, van Dam RM, Hu FB (2014) Long-term coffee consumption and risk of cardiovascular disease: a systematic review and a dose-response meta-analysis of prospective cohort studies. Circulation 129:643-659

20. Sugiyama K, Kuriyama S, Akhter M, Kakizaki M, Nakaya N, Ohmori-Matsuda K, Shimazu T, Nagai M, Sugawara Y, Hozawa A, Fukao A, Tsuji I (2010) Coffee consumption and mortality due to all causes, cardiovascular disease, and cancer in Japanese women. J Nutr 140:1007-1013

21. Gardener H, Rundek T, Wright CB, Elkind MS, Sacco RL (2013) Coffee and tea consumption are inversely associated with mortality in a multiethnic urban population. J Nutr 143:1299-1308

22. Lopez-Garcia E, Rodriguez-Artalejo F, Li TY, Mukamal KJ, Hu FB, van Dam RM (2011) Coffee consumption and mortality in women with cardiovascular disease. Am J Clin Nutr 94:218-224 
23. Grobbee DE, Rimm EB, Giovannucci E, Colditz G, Stampfer M, Willett W (1990) Coffee, caffeine, and cardiovascular disease in men. N Engl J Med 323:1026-1032

24. Papamichael CM, Aznaouridis KA, Karatzis EN, Karatzi KN, Stamatelopoulos KS, Vamvakou G, Lekakis JP, Mavrikakis ME (2005) Effect of coffee on endothelial function in healthy subjects: the role of caffeine. Clin Sci (Lond) 109:55-60

25. Buscemi S, Verga S, Batsis JA, Donatelli M, Tranchina MR, Belmonte S, Mattina A, Re A, Cerasola G (2010) Acute effects of coffee on endothelial function in healthy subjects. Eur J Clin Nutr 64:483-489

26. Buscemi S, Verga S, Batsis JA, Tranchina MR, Belmonte S, Mattina A, Re A, Rizzo R, Cerasola G (2009) Dose-dependent effects of decaffeinated coffee on endothelial function in healthy subjects. Eur J Clin Nutr 63:1200-1205

27. Shechter M, Shalmon G, Scheinowitz M, Koren-Morag N, Feinberg MS, Harats D, Sela BA, Sharabi Y, Chouraqui P (2011) Impact of acute caffeine ingestion on endothelial function in subjects with and without coronary artery disease. Am J Cardiol 107:1255-1261

28. Gaascht F, Dicato M, Diederich M (2015) Coffee provides a natural multitarget pharmacopeia against the hallmarks of cancer. Genes Nutr 10:51

29. Suzuki A, Fujii A, Jokura H, Tokimitsu I, Hase T, Saito I (2008) Hydroxyhydroquinone interferes with the chlorogenic acidinduced restoration of endothelial function in spontaneously hypertensive rats. Am J Hypertens 21:23-27

30. Shashni B, Sharma K, Singh R, Sakharkar KR, Dhillon SK, Nagasaki Y, Sakharkar MK (2013) Coffee component hydroxyl hydroquinone (HHQ) as a putative ligand for PPAR gamma and implications in breast cancer. BMC Genom 14(Suppl 5):S6

31. Ochiai R, Chikama A, Kataoka K, Tokimitsu I, Maekawa Y, Ohishi M, Rakugi H, Mikami H (2009) Effects of hydroxyhydroquinone-reduced coffee on vasoreactivity and blood pressure. Hypertens Res 32:969-974

32. Yamaguchi T, Chikama A, Mori K, Watanabe T, Shioya Y, Katsuragi Y, Tokimitsu I (2008) Hydroxyhydroquinone-free coffee: a double-blind, randomized controlled dose-response study of blood pressure. Nutr Metab Cardiovasc Dis 18:408-414

33. Fujimura N, Noma K, Hata T, Soga J, Hidaka T, Idei N, Fujii Y, Mikami S, Maruhashi T, Iwamoto Y, Kihara Y, Chayama K, Kato H, Liao JK, Higashi Y (2012) Mineralocorticoid receptor blocker eplerenone improves endothelial function and inhibits rho-associated kinase activity in patients with hypertension. Clin Pharmacol Ther 91:289-297

34. James PA, Oparil S, Carter BL, Cushman WC, Dennison-Himmelfarb C, Handler J, Lackland DT, LeFevre ML, MacKenzie
TD, Ogedegbe O, Smith SC Jr, Svetkey LP, Taler SJ, Townsend RR, Wright JT Jr, Narva AS, Ortiz E (2014) 2014 evidence-based guideline for the management of high blood pressure in adults: report from the panel members appointed to the Eighth Joint National Committee (JNC 8). JAMA 311:507-520

35. American Diabetes Association (2017) Classification and diagnosis of diabetes. Diabetes Care 40 (Suppl 1):S11-S24

36. Expert Panel on Detection, Evaluation, and Treatment of High Blood Cholesterol in Adults (2001) Executive Summary of the Third Report of the National Cholesterol Education Program (NCEP) Expert Panel on Detection, Evaluation, and Treatment of High Blood Cholesterol in Adults (Adult Treatment Panel III). JAMA 285:2486-2497

37. Ludwig IA, Mena P, Calani L, Cid C, Del Rio D, Lean ME, Crozier A (2014) Variations in caffeine and chlorogenic acid contents of coffees: what are we drinking? Food Funct 5:1718-1726

38. Maruhashi T, Soga J, Fujimura N, Idei N, Mikami S, Iwamoto Y, Kajikawa M, Matsumoto T, Hidaka T, Kihara Y, Chayama K, Noma K, Nakashima A, Goto C, Higashi Y (2013) Nitroglycerine-induced vasodilation for assessment of vascular function: a comparison with flow-mediated vasodilation. Arterioscler Thromb Vasc Biol 33:1401-1408

39. Montuschi P, Barnes PJ, Roberts LJ (2004) Isoprostanes: markers and mediators of oxidative stress. FASEB J 18:1791-1800

40. Umemura T, Ueda K, Nishioka K, Hidaka T, Takemoto H, Nakamura S, Jitsuiki D, Soga J, Goto C, Chayama K, Yoshizumi M, Higashi Y (2006) Effects of acute administration of caffeine on vascular function. Am J Cardiol 98:1538-1541

41. Mesas AE, Leon-Muñoz LM, Rodriguez-Artalejo F, Lopez-Garcia E (2011) The effect of coffee on blood pressure and cardiovascular disease in hypertensive individuals: a systematic review and metaanalysis. Am J Clin Nutr 94:1113-1126

42. Ding M, Satija A, Bhupathiraju SN, Hu Y, Sun Q, Han J, LopezGarcia E, Willett W, van Dam RM, Hu FB (2015) Association of coffee consumption with total and cause-specific mortality in 3 large prospective cohorts. Circulation 132:2305-2315

43. Onakpoya IJ, Spencer EA, Thompson MJ, Heneghan CJ (2015) The effect of chlorogenic acid on blood pressure: a systematic review and meta-analysis of randomized clinical trials. J Hum Hypertens 29:77-81

44. Libby P, Ridker PM, Maseri A (2002) Inflammation and atherosclerosis. Circulation 105:1135-1143

45. Bhagat K, Vallance $P$ (1997) Inflammatory cytokines impair endothelium-dependent dilatation in human veins in vivo. Circulation 96:3042-3047 